\title{
Mitochondrial DNA Variation and the Origins of the Aleuts
}

\author{
ROHINA RUBICZ, ${ }^{1}$ THEODORE G. SCHURR, ${ }^{2}$ PAUL L. BABB,${ }^{2}$ AND \\ MICHAEL H. CRAWFORD ${ }^{1}$
}

\begin{abstract}
The mitochondrial DNA (mtDNA) variation in 179 Aleuts from five different islands (Atka, Unalaska, Umnak, St. Paul, and St. George) and Anchorage was analyzed to better understand the origins of Aleuts and their role in the peopling of the Americas. Mitochondrial DNA samples were characterized using polymcrase chain reaction amplification, restriction fragment length polymorphism analysis, and direct sequencing of the first hypervariable segment (HVS-I) of the control region. This study showed that Aleut mtDNAs belonged to two of the four haplogroups ( $A$ and $D$ ) common among Native Americans. Haplogroup $D$ occurred at a very high frequency in Aleuts, and this, along with their unique HVS-I sequences, distinguished them from Eskimos, Athapaskan Indians, and other northern Amerindian populations. While sharing several control region sequences (CIR11, CHU14, CIR60, and CIR61) with other circumarctic populations, Aleuts lacked haplogroup $A$ mtDNAs having the $16265 \mathrm{G}$ mutation that are specific to Eskimo populations. $R$-matrix and median network analyses indicated that Aleuts were closest genetically to Chukotkan (Chukchi and Siberian Eskimos) rather than to Native American or Kamchatkan populations (Koryaks and Itel'men). Dating of the Beringian branch of haplogroup A (16192T) suggested that populations ancestral to the Aleuts, Eskimos, and Athapaskan Indians emerged approximately 13,120 years ago, while Aleut-specific $A$ and $D$ sublineages were dated at $6539 \pm 3511$ and $6035 \pm 2885$ years, respectively. Our findings support the archacologically based hypothesis that ancestral Aleuts crossed the Bering Land Bridge or Beringian platform and entered the Alcutian Islands from the east, rather than island hopping from Kamchatka into the western Aleutians. Furthermore, the Aleut migration most likely represents a separate event from those responsible for peopling the remainder of the Americas, meaning that the New World was colonized through multiple migrations.
\end{abstract}

Our study focuses on the origin of the Aleuts, an Alaskan population located near the entry point into the Americas. The people who first settled the Aleutian Islands are believed to have entered the region sometime after 12,000 BP. Prior to this time, the area was covered by a sheet of ice cxtending from the Wisconsin

\footnotetext{
'Department of Anthropology, University of Kansas, Lawrence, KS 66045.

${ }^{2}$ Department of Anthropology, University of Pennsylyania, Philadelphia, PA 19104.
}

Hantan Biology, December 2003, v. 75, no. 6, pp. 809-835

Copyright 2004 Wayne State University Press, Detroit, Michigan 48201-1309

KEY WORDS: NATIVE: AMERICANS, SIBERIANS, PEOPLING OH AMERICAS, MTDNA, HAP' I.OGROUPS, SEQUENCES 
glacier (Black 1974). Beginning in 1741, at the time of Russian contact, it was thought that the Aleutian Islands were peopled by a population expansion from the Kamchatka Peninsula into the western islands (Laughlin and Marsh 1951). Later, Laughlin (1963) proposed that a population ancestral to both Aleuts and Eskimos migrated into the New World by way of the Bcring Land Bridge. Accordingly, upon arriving in Alaska, this population split into the Eskimos, who traveled northward, and the Aleuts, who moved into the eastern Alcutians from the southeastern tip of the Bering Land Bridge when sea levels were lower.

The archaeological evidence supports Laughlin's hypothesis. The oldest habitation sites in this archipelago, which date to around $8500 \mathrm{BP}$, are located in the eastern Aleutians, whercas all of the oldest sites located in the western islands are younger (Laughlin 1980; Knecht and Davis 2001). However, while agreeing that there were migrations of people into the Aleutians from the east, scholars from the former Soviet Union also suggest that there were numerous other movements into the islands, including several from northeast Asia (Black 1983).

In general, research into the relationship of Aleuts to populations on either side of the Bering Strait has generated conflicting results. Linguistic, morphological, and genetic (blood groups and serum loci) evidence indicates that the Aleuts are more similar to Eskimo groups (Bergsland 1959; Laughlin 1980; Marsh and Swadesh 1951). However, dental traits, other discrete cranial traits, and molecular evidence suggest that the Aleuts are more closely related to Amerindians (Merriwether et al. 1995; Ouslcy 1995; Szathmary and Ossenberg 1978; Turner 1983). At the same time, archacological and ethnohistorical data support a closer relationship between Aleuts and Siberian populations (Hrdlicka 1945; Black 1983). Thus, further resolution of the relationship between Aleuts and populations living on both sides of the Bering Strait is clearly warranted.

To elucidate the genetic prehistory of the Aleuts, we characterized their mitochondrial DNA (mtDNA) variation using restriction fragment length polymorphism (RFLP) analysis and sequencing of the first hypervariable segment of the control region (HVS-I). Through these methods, it has been shown that the mtDNAs of Native American populations belong to one of five founding haplogroups, called haplogroups $A-D$ and $X$ (Schurr et al. 1990; Torroni ct al. 1992, 1993a; Forster et al. 1996; Brown et al. 1998). The frequency of these haplogroups varies in different regions of the Americas, with native populations from northern North America having the highest frequencies of haplogroup $A$. Because of the large body of published mtDNA data that are now available, it was possible to compare them with those collected in this analysis and determine which Native American or Siberian populations had the closest genetic similarities to the Aleuts. Such data also allowed the testing of competing hypotheses for the settlement of the Aleutian Archipelago, i.e., whether there were genetic links between Aleuts and Kamchatkan populations, or, instead, between Aleuts and other Native Americans.

In a previous study of Aleuts from St. Paul Island in the Pribilofs, Merriwether et al. (1995) showed that this population had primarily haplogroup $A$ and 
$D$ mtDNAs. This finding is consistent with those from other studies showing these two haplogroups primarily in circumarctic populations (Ward et al. 1991; Torroni et al. 1992, 1993a; Shields et al. 1993; Starikovskaya et al. 1998; Schurr et al. 1999). In addition, the St. Paul Aleuts also exhibited low frequencies of haplogroup $C$ and 'other' mtDNAs. However, all of their mtDNAs were screened only for the RFLP markers defining haplogroups A-D and not subjected to HVSI sequencing. As a result, it was impossible to determine the exact genetic affinities of Aleuts to other circumarctic populations using these data.

Our preliminary molecular analyses of Aleut mtDNAs from individuals living in the Aleutian Archipelago generally confirmed the pattern of variation seen in the St. Paul Alcuts, although revealing only haplogroup $A$ and $D \operatorname{mtDNAs}$ in Aleutian individuals (Rubicz et al. 2000, 2001; Rubicz 2001). They also indicated that most, if not all, of the haplogroup $D$ mtDNAs belonged to the $D 2$ subtype defined by Forster et al. (1996). However, a more extensive analysis of these mtDNAs was needed to fully characterize the diversity in this population. This report summarizes our expanded analysis, and discusses the implications of the new mtDNA data for the genetic prehistory of the Alcuts.

\section{Subjects and Methods}

Population. The Aleuts traditionally inhabited the length of the Alcutian archipelago. However, after contact with Russians beginning in 1741, the original population experienced a number of distuptive cvents. Infectious diseases brought by early explorers and fur traders, as well as warfare with Russians, decimated this population. Although the Aleut population has increased in number during recent years, it remains a fraction of its precontact size, which has been estimated at 15,000-20,000 persons (Lantis 1984). During Russian control of the archipelago, some Aleuts were relocated to the previously uninhabited Pribilof Islands, north of the Aleutians, and to the Commander Islands proximal to the Kamchatkan Peninsula. Later, during World War II, the inhabitants of Attu were taken to Japan, and the US government further disrupted island communities by evacuating all Aleuts to the Alaskan mainland. Because of these events, admixture with non-Aleut males has occurred, first with Russians, and later with both natives and nonnatives from the American contincnt. Today, the Aleuts reside mainly in the eastern Aleutians, the Pribilofs, and the Alaska mainland, as well as Bering Island in the Commander Islands, Russia.

Samples. This study was approved by the University of Kansas Advisory Committee on Human Experimentation and several Aleut tribal organizations (Aleutian/Pribilof Island Association, Aleut Corporation, and tribal councils). Samples were collected from 179 Aleuts living in five, small Alaskan communities and one city (Figure 1). These included 17 from Atka, 17 from Umnak Island (Nikolski), and 37 from Unalaska (in the central and eastern Aleutians); 32 from 


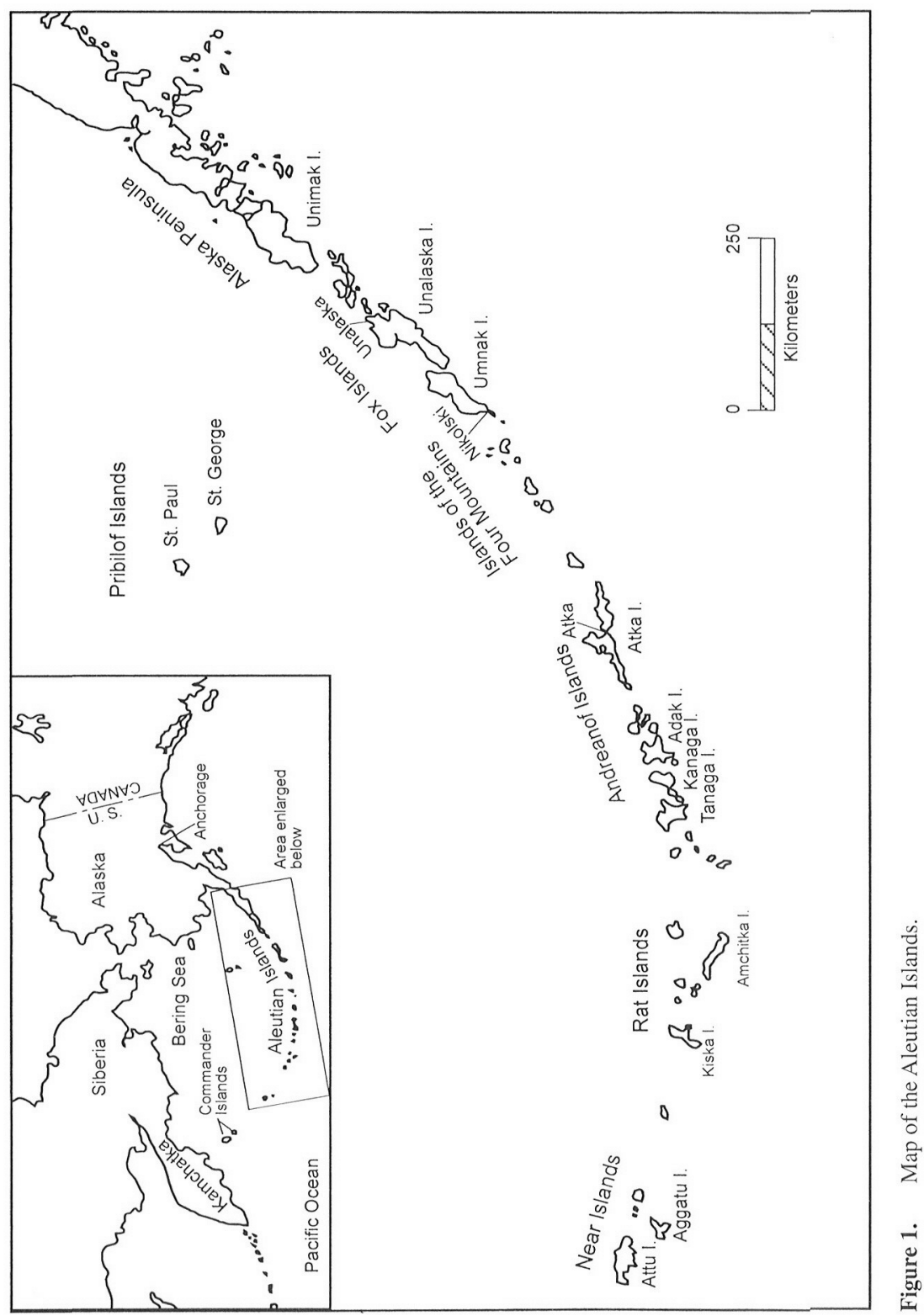


St. George and 47 from St. Paul (in the Pribilofs); and 29 from Anchorage. Each participant was interviewed to obtain family background information (including birth locations), and to control for admixture by confirming Aleut ancestry on his or her maternal side. Cheek cell samples from the first 50 individuals were collected using OraSure kits (Analytical Genetic Testing Center, Denver, CO). The remaining samples were collected with sterile wooden applicators and stored in Tris-EDTA buffer. DNA was isolated from the samples using either OraSure extraction kits or the standard phenol-chloroform method.

MtDNA Analysis. All 179 Aleut mtDNAs were surveyed for RFLPs diagnostic of the four major Native American mtDNA haplogroups through polymerase chain reaction (PCR) amplification of short segments encompassing these polymorphisms and restriction analysis. The polymorphisms analyzed included HaellI np 663 site gain (haplogroup $A$ ), 9-base-pair (bp) deletion (haplogroup $B$ ), the combined HincII np 13259 site loss and AluI 13262 site gain (haplogroup C), and AluI np 5176 site loss (haplogroup $D$ ). The primer pairs and amplification conditions used for this analysis are described by Torroni et al. (1993). Restriction fragments were electrophoresed on NuSieve plus SeaKem agarose gels (FMC BioProducts) and photodocumented under UV-induced fluorescent light. In addition, for 163 of the samples, approximately $400 \mathrm{bp}$ (np 16000-16400) of the HVS-I region were directly sequenced using Big Dye Terminator Kits (PE-Applied Biosystems) and the primers and conditions given in Schurr et al. (1999). Sequence data were collected and analyzed using the SEQED software included in the ABI 377 DNA Sequencer, and alignments and comparisons of the HVS-I sequences were made using Sequencher 3.1.1 software (Gene Codes Corporation).

\section{Analytical Procedures.}

Admixture Estimates. To assess the level of admixture in previously analyzed St. Paul Alcuts (Merriwether et al. 1995), the haplogroup frequencics from this population were analyzed using Bernstein's classical model (Bernstein 1931). This method assumes known allelic frequencies $(P)$ in two parental populations, $A$ and $B$, each contributing $M$ and $1-M$ proportions to the hybrid population. The proportion of admixture is then estimated as $M=\left(P_{M}-P_{B} / P_{A}-P_{B 3}\right)$. The details of this method can be found in Cavalli-Sforza and Bodmer (1971).

Relationship Matrix (R-Matrix). The RFLP frequency data were analyzed with the $R$-matrix method to visualize the relationship of the Aleuts to other populations, which are listed in Table 1. A variance-covariance matrix of genetic similarity and dissimilarity between population subdivisions was constructed using ANTANA (Harpending and Rogers 1984), and the frequencies of alleles (mIDNA haplotypes) were plotted to examine their relative contributions to the population distributions. In addition, an $R$-matrix analysis based on frequencies of HVS-I sequence mutations was run for comparison. For this analysis, the following popu- 
Table 1. Mitochondrial DNA Haplogroup Frequencies based on RFLPs

\begin{tabular}{lrcccccc} 
Population & $n$ & $m t D N A * A$ & $m t D N A * B$ & $m t D N A * C$ & $m t D N A * D$ & $m t D N A * O T$ & Reference \\
\hline Itel'men & 47 & $6.4 \%$ & $0 \%$ & $14.9 \%$ & $0 \%$ & $78.7 \%$ & 3 \\
Koryak & 155 & $5.2 \%$ & $0 \%$ & $36.1 \%$ & $1.3 \%$ & $57.4 \%$ & 3 \\
Chukchi & 24 & $37.5 \%$ & $0 \%$ & $16.7 \%$ & $16.7 \%$ & $29.2 \%$ & 6 \\
Siberian Yupik & 50 & $80.0 \%$ & $0 \%$ & $0 \%$ & $20.0 \%$ & $0 \%$ & 6 \\
Inuit & 30 & $96.7 \%$ & $0 \%$ & $0 \%$ & $3.3 \%$ & $0 \%$ & 1 \\
Aleut & $\mathbf{1 7 9}$ & $\mathbf{2 8 . 5 \%}$ & $\mathbf{0 \%}$ & $\mathbf{0 \%}$ & $\mathbf{7 1 . 5 \%}$ & $\mathbf{0 \%}$ & This study \\
Aleut (Pribilof & & & & & & & \\
$\quad$ Island) & 78 & $25.0 \%$ & $0 \%$ & $1.4 \%$ & $66.7 \%$ & $6.9 \%$ & 2 \\
Dogrib & 42 & $100 \%$ & $0 \%$ & $0 \%$ & $0 \%$ & $0 \%$ & 1,4 \\
Haida & 25 & $96.6 \%$ & $0 \%$ & $0 \%$ & $3.4 \%$ & $0 \%$ & 1,5 \\
Bella Coola & 36 & $50.0 \%$ & $5.6 \%$ & $13.9 \%$ & $25.0 \%$ & $5.6 \%$ & 1,5 \\
Nuu-Chan-Nulth & 15 & $40.0 \%$ & $6.7 \%$ & $13.3 \%$ & $26.7 \%$ & $13.3 \%$ & 5 \\
\hline
\end{tabular}

References: (1) Lorenz and Smith 1996; (2) Merriwether et al. 1995; (3) Schurr et al. 1999; (4) Torroni et al. 1992; (5) Torroni et al. 1993a; (6) Torroni et al. 1993b.

lations were used: Koryaks and Itel'men (Schurr et al. 1999), Chukchi and Siberian Yupik (Starikovskaya et al. 1998), Alaskan Athapaskans and Yakima (Shields et al. 1993), Haida and Bella Coola (Ward et al. 1993), West Greenland Eskimo (Saillard et al. 2000), and Nuu-Chah-Nulth (Ward et al. 1991). It was not possible to examine the same populations in the two $R$-matrix analyses because comparable data (RFLP and HVS-I) were not always available for them.

Median Network Analysis. Median network analysis was used to construct genealogies of HVS-I sequence data (Network 3.1, Fluxus Engineering) (Bandelt et al. 1995). This method is considered more suitable for analyzing nonrecombining data at the intraspecific level (such as human mtDNA sequences) than traditional phylogenetic methods. HVS-I sequence data were taken from the Aleuts described in this study and populations described in published studies, including the Itel'men and Koryaks (Schurr et al. 1999), Chukchi and Siberian Eskimos (Starikovskaya et al. 1998), Alaskan Inupik/Yupik (Shields et al. 1993), Greenland Eskimos (Saillard et al. 2000), Haida and Bella Coola (Ward et al. 1993), Yakima (Shields et al. 1993) and Nuu-Chah-Nulth (Ward et al. 1991). Because only Siberian populations were surveyed for high resolution-RFLP (HR-RFLP) analysis, these kinds of data were not used in these analyses. However, low resolution-RFLP (LR-RFLP) data, that is, those RFLPs that define haplogroups $A-D$ and $X$, were used in some of the analyses to test their influence on the branching patterns of the networks.

When all of the published HVS-I sequences from circumarctic populations were used with this program, the resulting networks were large and reticulated. These results were likely attributable to several factors, including the large number of sequences present in the data matrix, the effects of recurrent mutations in 
closely related sequences from the same haplogroup, problems with some of the data sets (i.e., too many mutations at the ends of HVS-I sequences in the data sets of Ward et al. [1991, 1993] and Shields et al. [1993], as per the comments of Saillard et al. [2000]); and the recent expansion of haplogroups $A$ and $D$, which produced a number of sequences only one or two mutational steps different from ancestral (nodal) types. For this reason, the Aleut data were compared with a selection of northeastern Siberians and Native Americans to clarify the phylogenetic relationships among them. In addition, the mutations that defined the HVSI sequence motifs for the different haplogroups (e.g., 16223T, 16298C, and $16327 \mathrm{~T}$ for haplogroup $C$ ) were given twice the statistical weight of the other polymorphisms that appeared in these haplotypes. The networks obtained through this weighting approach were relatively close in form to those obtained without any character weighting, and essentially the same as those based on haplotypes defined with both LR-RFLP and HVS-I sequence data.

For most of the analyses discussed in this paper, only Chukchi and Siberian Yupik (Starikovskaya et al. 1998), Alaskan Yupik/Inupik (Shiclds et al. 1993), Greenland Eskimos (Saillard et al. 2000), and Aleuts (this study) were used. Overall, these samples were the best provenienced ethnographically, the largest in number per population, the most thoroughly analyzed for sequence variation (by both HVS-I sequencing and RFLP analysis), and the least problematic in terms of potential errors in the HVS-I sequence data. In addition, they represented a broad spectrum of circumarctic populations that were known to have biological and cultural similarities, based on previous anthropological studies. However, for the haplogroup $D$ analysis, data from the Yakima (Shields et al. 1993), Haida and Bclla Coola (Ward et al. 1993), and Nuu-Chah-Nulth (Ward et al. 1991) were also employed, since there are relatively few sequences from this haplogroup in circumarctic populations outside of the Aleuts.

Time Estimates. The coalescence dates for particular clusters of HVS-I sequences from haplogroups $A$ and $D$ were estimated using dating option of Network 3.1 and an HVS-I mutation rate of 20,180 years per mutation (Forster et al. 1996; Saillard et al. 2000). These haplogroups were analyzed because of their prevalence in circumarctic populations, as well as the limited number of haplogroup $B, C$, and $X$ mtDNAs (and those seen in NE Siberians- $G, Y, Z$ ) in Aleuts and related groups. The divergence of these two haplogroups is, therefore, vicwed as being most closely linked to the evolution of circumarctic populations. This approach allowed the dating of the main points of divergence in these haplogroups that potentially paralleled the emergence of major linguistic stocks or ethnic populations (e.g., Eskimo-Aleuts).

\section{Results}

MtDNA Haplogroup Frequencies. The RFLP analysis of Aleut mtDNAs revealed that they belonged to only two of the four haplogroups common among 
Native Americans, $A$ and $D$. Haplogroup $A$ represented $28.5 \%$ of these mtDNAs, while haplogroup $D$ constituted the rest. No nonnative mtDNA haplogroups were identified in this sample. These frequencies are similar to those observed in the St. Paul Alcuts (Merriwether et al. 1995), except for the presence of haplogroup $C$ and 'other' haplotypes found in this population. Given that the St. Paul community was settled during historic times by not only Aleuts but also other Native Americans (including Eskimos and Athapaskan Indians) and nonnatives, it is likely that the miDNAs not belonging to haplogroups $A$ and $D$ in the previous study are the result of admixture. This interpretation is supported by an ongoing genetic study of ancient Aleut samples, which show that only $A$ and $D$ haplotypes are present in them (Hayes 2002; Hayes and O'Rourke 2000; O'Rourke et al. 2000).

Nevertheless, to test this interpretation, we computed admixture levels in the St. Paul Alcuts based on the incidence of haplogroup $C$ in this population. This estimate suggested that $10.5 \%$ of the St. Paul gene pool was attributable to gene flow from Athapaskan Indians, in which this haplogroup appears. However, these mtDNAs may have come from Amerindian populations, as we noted the intermarriage of Sioux and Athapaskan individuals among the Aleut families with whom we worked. Similarly, the presence of 'other' mtDNA haplogroups suggests that $0.07 \%$ of the mtDNAs in St. Paul Aleuts came from European females (assuming that 'other' represents European gene flow into the community). Thus, a small but nontrivial proportion of St. Paul Aleut mtDNAs appears to be nonAleut in origin. These findings highlight the importance of collecting accurate genealogical data when conducting molecular anthropological studies.

Table I compares the Aleut mtDNA haplogroup frequencies with those of nine other circumarctic groups, including five Native American populations (Alaskan Inupik, Dogrib, Haida, Bella Coola, and Nuu-Chah-Nulth) and four Siberian populations (Itel'men, Koryaks, Chukchi, and Siberian Yupik). Population locations for these and other groups mentioned in the text are given in Figure 2. The Aleuts differed from all of the other populations in that they exhibited a high frequency of haplogroup $D$. By contrast, haplogroup $A$, the most prevalent mtDNA lineage in circumarctic populations, was present only in moderate frequencies in the Aleuts. While haplogroups $B$ and $C$ were found in a few circumarctic populations, they generally exist only at low frequencies (with the exception of haplogroup $C$ in the Koryaks, Itel'men, and Chukchi). This low frequency raises the possibility that admixture was responsible for their presence in these populations.

HVS-I Sequencing. The results of the HVS-I sequencing of 163 individuals are listed in Table 2. Overall, the Alcuts had 26 different HVS-I haplotypes characterized by 23 variable sites. Haplotype $A L 20$ (belonging to haplogroup $D$ ) was the most common lineage, being present in 79 individuals, followed by $A L O I$ (belonging to haplogroup $A$ ) in 24 individuals. The majority of the mutations were transitions, and only two transversions were present. The $16362 \mathrm{~T} \rightarrow \mathrm{C}(\mathrm{I} 6362 \mathrm{C})$ 
MiDNA Variation and the Origins of the Aleuts / 817

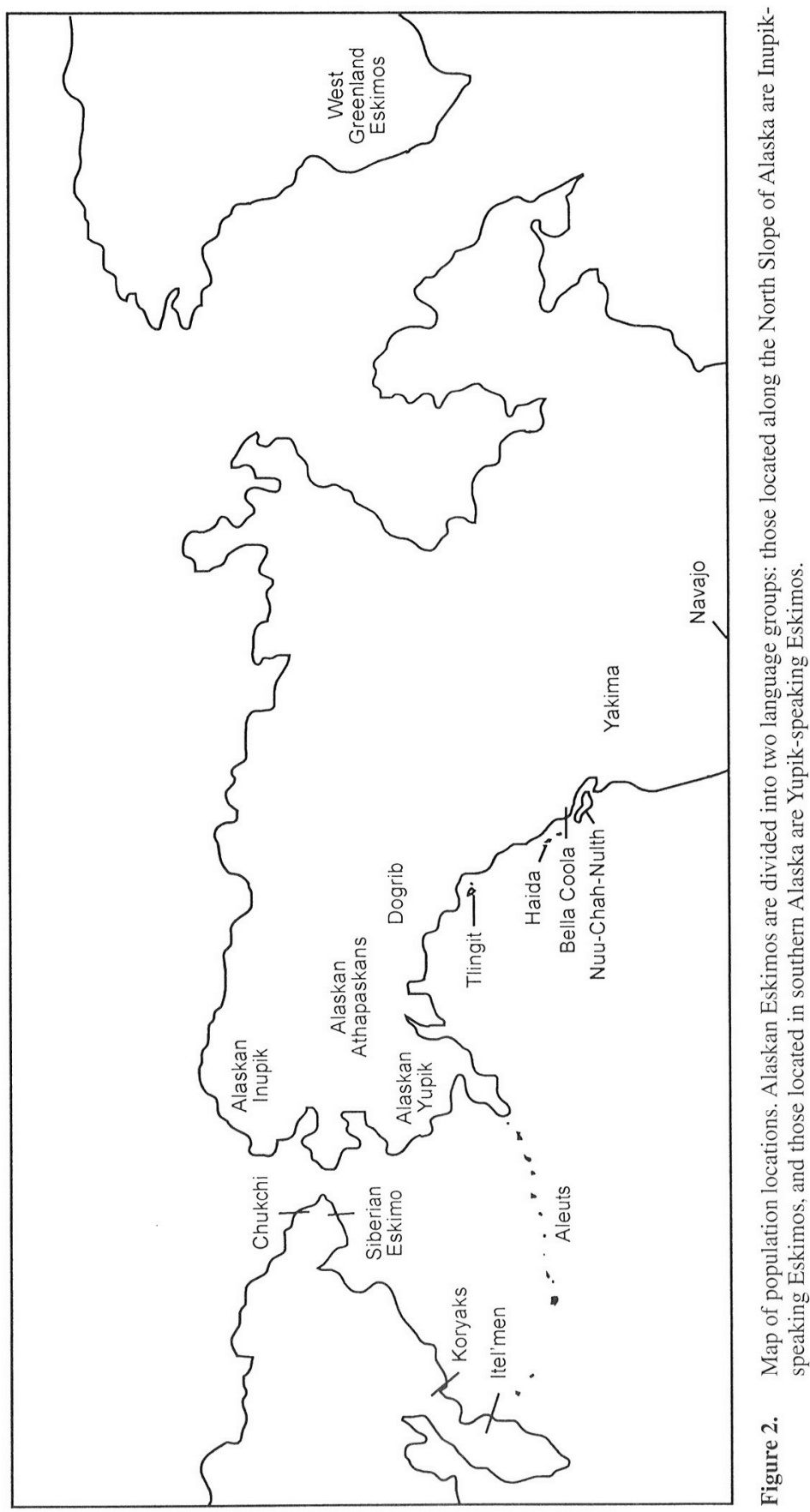

Reproduced with permission of the copyright owner. Further reproduction prohibited without permission. 
818 / RUBICZ E'T AL.

Table 2. Aleut HVS-I Sequences

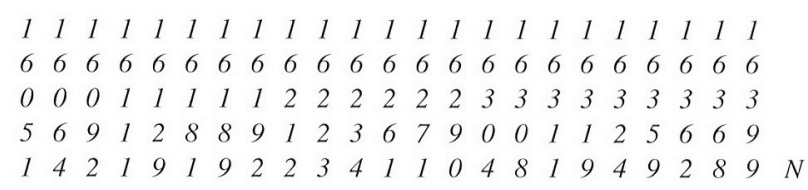

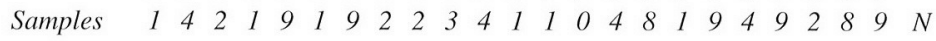

\begin{tabular}{|c|c|c|c|c|c|c|c|c|c|c|c|c|c|c|c|c|c|c|c|c|c|}
\hline$A M$ & A & $\mathrm{T}$ & $\mathrm{TC}$ & $\mathrm{C} \mathrm{G}$ & A & $\mathrm{T}$ & $\mathrm{C}$ & A $C$ & $\mathrm{C} \mathrm{C}$ & $\mathrm{C}$ & 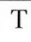 & C & & & ( & $\mathrm{T}$ & $\mathrm{T} T$ & $\mathrm{~T}$ & & & \\
\hline ALO1 & . & . & . $\mathrm{T}$ & T & . & . & $\mathrm{T}$ & G & $\mathrm{T}$. & . & & $\mathrm{T}$ & & & A & . & . $\mathrm{C}$ & $=$ & . & 24 & Haplogroup A \\
\hline ALO2 & G & & . $\mathrm{T}$ & T & . & . & $\mathrm{T}$ & G & $\mathrm{T}$ & . & & $\mathrm{T}$ & & & A & . & . $\mathrm{C}$ & E. & . & 5 & \\
\hline ALO3 & . & . & . $\mathrm{T}$ & T & . & . & $\mathrm{T}$ & & $\mathrm{T} \mathrm{T}$ & . & . & $\mathrm{TC}$ & & & A & . & . $\mathrm{C}$ & $\therefore$. & . & 5 & \\
\hline AL04 & . & . & . $\mathrm{T}$ & $\Gamma$. & . & . & $\mathrm{T}$ & & T. & . & . & $\mathrm{T}$ & & . & A & . & . $\mathrm{C}$ & $\therefore$ & . & 4 & \\
\hline AL05 & . & . & . $\mathrm{T}$ & T. & . & . & $\mathrm{T}$ & & $\mathrm{T}$ & . & . & . & & & A & . & . $\mathrm{C}$ & E. & . & 3 & \\
\hline AL06 & . & . & . $\mathrm{T}$ & T. & . & . & $\mathrm{T}$ & $\mathrm{T}$ & $\mathrm{T} \mathrm{T}$ & . & . & $\mathrm{T}$ & & . & . A & . & . $\mathrm{C}$ & C. & . & 2 & \\
\hline AL07 & . & . & . $\mathrm{T}$ & T. & . & . & & G $T$ & $\mathrm{~T}$. & & . & $\mathrm{T}$ & & & $\mathrm{CA}$ & . & . $\mathrm{C}$ & C. & . & 1 & \\
\hline AL08 & . & 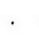 & . $\mathrm{T}$ & T. & . & $\mathrm{C}$ & . & G $T$ & $\mathrm{~T}$. & & . & $\mathrm{T}$ & & . & A & . & . $\mathrm{C}$ & & . & 1 & \\
\hline ALO9 & . & . & . $\mathrm{T}$ & T. & . & . & $\mathrm{T}$ & G & $\mathrm{T}$. & & . & $\mathrm{T}$ & . & . & . A & . & $\mathrm{C} \mathrm{C}$ & C. & . & 2 & \\
\hline AL10 & . & . & . $\mathrm{T}$ & T. & . & . & . & G & $\mathrm{T}$. & . & . & $\mathrm{T}$ & . & . & A & . & . $\mathrm{C}$ & c & . & 1 & \\
\hline AL1I & . & 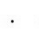 & . $\mathrm{T}$ & $\Gamma$. & & $\mathrm{C}$ & . & .7 & $\mathrm{~T} \mathrm{~T}$ & . & . & $\mathrm{T} \mathrm{C}$ & & & A & . & . $\mathrm{C}$ & & . & 1 & \\
\hline AL12 & . & . & . $\mathrm{T}$ & $\Gamma$. & . & . & . & .7 & $\mathrm{~T} \mathrm{~T}$ & . & . & $\mathrm{T}$ & & 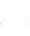 & A & . & . $\mathrm{C}$ & & . & 1 & \\
\hline AL13 & . & . & . $\mathrm{T}$ & $\Gamma$. & . & . & . & .7 & $\mathrm{~T}$ & . & . & $\mathrm{T}$ & & & A & . & . $\mathrm{C}$ & & . & 1 & \\
\hline AL14 & . & & . $\mathrm{T}$ & $\Gamma$. & . & . & $\mathrm{T}$ & 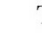 & T. & $\mathrm{T}$ & . & $\mathrm{T}$ & & & A & . & . $\mathrm{C}$ & & . & 1 & \\
\hline AL15 & . & . & . $\mathrm{T}$ & $\Gamma$. & . & . & $\mathrm{T}$ & . & . & $\mathrm{T}$ & . & $\mathrm{T}$ & & & A & . & . $\mathrm{C}$ & & . & 1 & \\
\hline AL17 & . & C & . $\mathrm{T}$ & $\Gamma$. & & . & $\mathrm{T}$ & . & $\mathrm{T}$ & . & . & $\mathrm{T}$ & & & A & . & . $\mathrm{C}$ & & . & 1 & \\
\hline AL18 & . & & . $\mathrm{T}$ & $\Gamma$ & & . & $\mathrm{T}$ & . & $\mathrm{T}$ & . & . & $\mathrm{T}$ & & & $\mathrm{A}$ & & . $\mathrm{C}$ & & . & 1 & \\
\hline AL19 & . & & . $\mathrm{T}$ & $\Gamma$ & & . & $\mathrm{T}$ & . & $\mathrm{T}$ & & . & $\mathrm{T}$ & & & A & G & . $\mathrm{C}$ & & . & 1 & \\
\hline AL2O & & . & . . & . A & & . & . & .7 & T & & C & & & & . & . & . $\mathrm{C}$ & E. & . & 79 & Haplogroup D \\
\hline AL2I & & . & . & . A & & . & & .7 & $\mathrm{~T}$ & & C & & & & & . & . $\mathrm{C}$ & $\mathrm{C}$. & G & 11 & \\
\hline AL22 & . & . & . & . $\mathrm{A}$ & & . & . & & & . & C & . & & & . & . & . C & C & . & 7 & \\
\hline AL23 & . & . & . & . $\mathrm{A}$ & & . & . & . & T & . & C & . & & & $=$ & . & . $\mathrm{C}$ & $\mathrm{C}$ & . & 5 & \\
\hline AL24 & . & & . & . A & & . & . & .7 & T & r & C & . & & & . & . & . $\mathrm{C}$ & $\mathrm{CC}$ & . & 2 & \\
\hline AL25 & . & & & - $A$ & & . & & . & & . & C & & & & . & $\cdot$ & . C & C & . & 1 & \\
\hline AL26 & . & 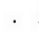 & A & . $\mathrm{A}$ & & . & & .7 & $\mathrm{~T}$ & & C & . & & & . & . & . $\mathrm{C}$ & C & . & 1 & \\
\hline AL27 & . & . & . . & . A & G & . & . & & $\cdot$ & . & C & & & & . & . & C & $C$ & & 1 & \\
\hline
\end{tabular}


transition was present in all Aleut haplotypes regardless of whether they belonged to haplogroup $A$ or $D$.

All of the Aleut $A$ haplotypes had the np $16111 \mathrm{C} \rightarrow \mathrm{T}$ (16111T) transition, which is characteristic of most Native American and Chukotkan (Chukchi and Siberian Eskimo) and a few Kamchatkan (Koryak and Itel'men) mtDNAs, but not of other Siberian and Asian haplotypes from this lineage (Schurr et al. 1999; Schurr and Wallace 1999; Starikovskaya et al. 1998; Torroni et al. 1993b). This mutation is part of the sequence motif (16111T-16223T-16290T-16319A$16362 \mathrm{C}$ ) that defines the $A 2$ subtype of Forster et al. (1996). Most of the $A$ haplotypes in this sample also had the Beringian-specific $16192 \mathrm{C} \rightarrow \mathrm{T}(16192 \mathrm{~T})$ transition (Schurr et al. 1999), a mutation that helps to define the sequence motif of the A3 subtype (16111T-16192T-16223T-16290T-16319A-16362). The majority of Alcut A HVS-I sequences derive from the $A 3$ subgroup. Furthermore, several Aleut $A$ haplotypes were characterized by $16212 \mathrm{~A} \rightarrow \mathrm{G}(16212 \mathrm{G})$ and $16234 \mathrm{C} \rightarrow \mathrm{T}$ (16234T) transitions, both of which appear to be Aleut-specific. However, none of them exhibited the Eskimo-specific $A 4$ subtype defined by np $16265 A \rightarrow G$ (16265G) transition (Shields et al. 1993; Starikovskaya et al. 1998; Saillard et al. 2000 ), or the Athapaskan-specific $16331 \mathrm{~A} \rightarrow \mathrm{G}(16331 \mathrm{G})$ transition (Shields et al. 1993; Torroni et al. 1993a; Starikovskaya et al. 1998).

Aleut $D$ sequences all had $n p 16129 \mathrm{G} \rightarrow \mathrm{A}(16129 \mathrm{~A})$ and $\mathrm{np} 16271 \mathrm{~T} \rightarrow \mathrm{C}$ (16271C) transitions. Most of these belonged to the $D 2$ subtype described by Forster et al. (1996), which is defined by the 16223T-16271C-16362C motif. The D2 subtype has previously been described in the Chukchi and Siberian Eskimos (Starikovskaya et al. 1998), as well as one Alaskan Athapaskan Indian (Shields et al. 1993), but is absent from Greenland Eskimos and Kamchatkan populations (Saillard et al. 2000; Schurr et al. 1999). Based on the HR-RFLP data from the Chukchi and Siberian Eskimos (Chukotkan haplotypes, SIB48-52; Starikovskaya et al. 1998), as well as the whole mtDNA genome sequence data of Derbeneva et al. (2002), we predict that all of the Aleut D2 mtDNAs will also have the Hae III 3315 site loss and $A l u \mathrm{I} 8683$ site gain.

The Aleuts shared several HVS-I haplotypes with other populations (Table 3). In Table 3, the sequences with the abbreviation "CIR" (Circumarctic) come from Ward et al. $(1991,1993)$ and Shields et al. (1993), and their numbers correspond to the identifications given in those papers. Those having a "CIIU" (Chukotkan) abbreviation come from Starikovskaya et al. (1998) for Chukchi and Siberian Eskimos, and correspond to the numbering given in Table 4 of that paper. Aleut sequences were assigned an "AL" abbreviation.

Haplotypes ALO4 and ALI4 correspond to haplotypes CIR6I and CIR60, respectively, which are frequent in circumarctic populations. In addition, $A L I 3$ corresponds to CIR/I, which is the most prevalent HVS-I sequence in Native American populations and represents the founder haplotypes for haplogroup $A$ (haplotype $A 2$ ). AL20, which accounts for the majority of individuals in this sample, corresponds to haplotype $\mathrm{CHUJ4}$, also present in the Chukchi and Siberian 
$820 /$ RUBICZ ET AL.

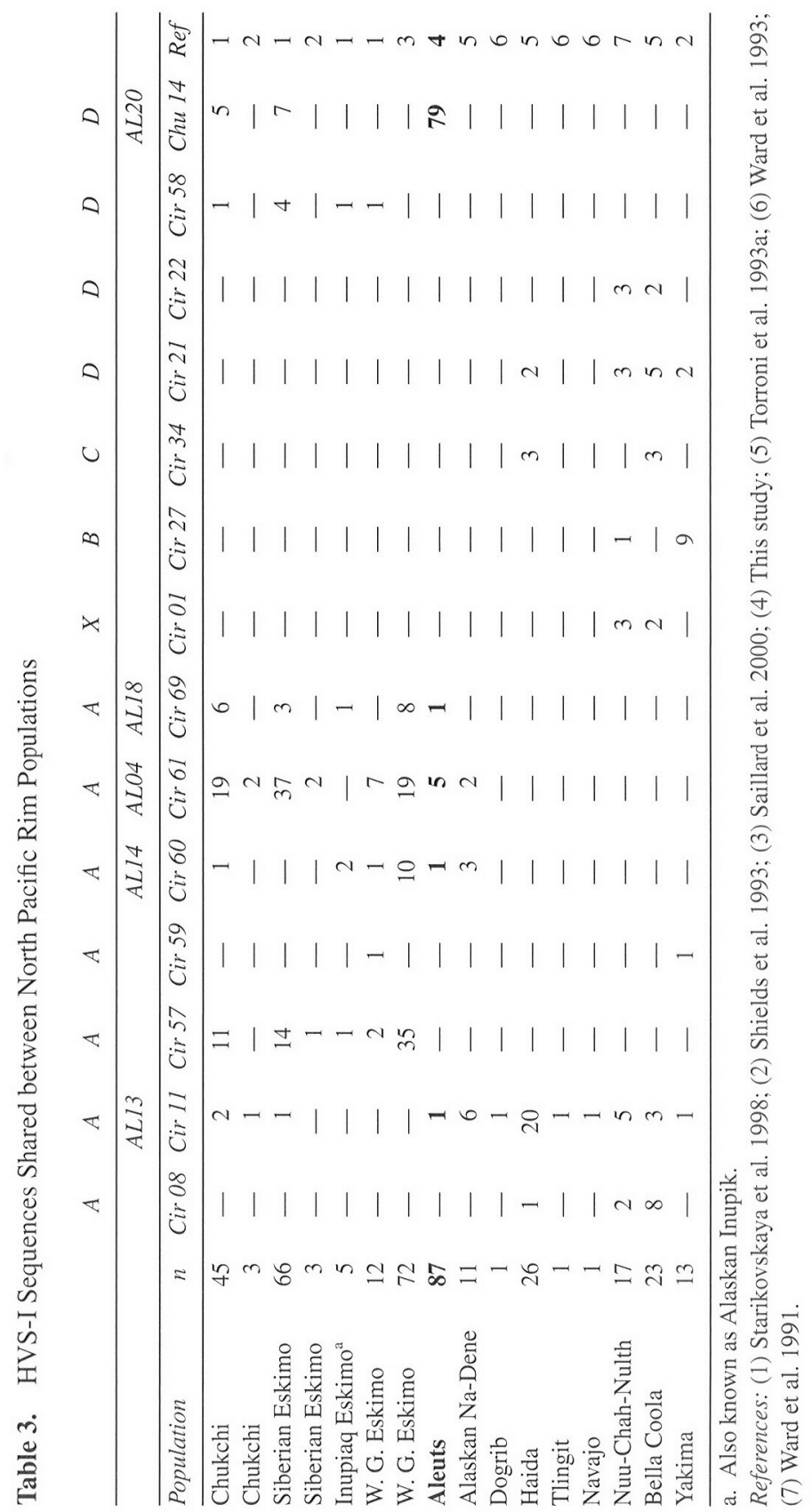




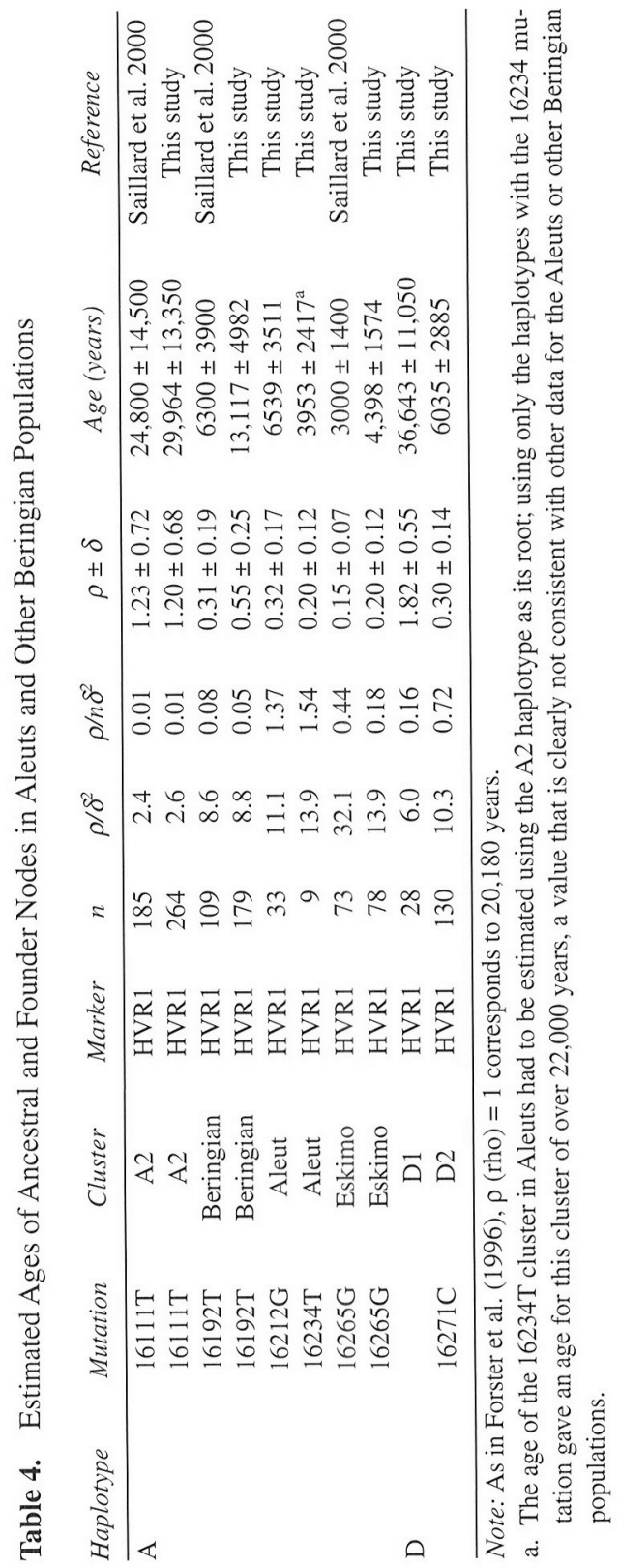




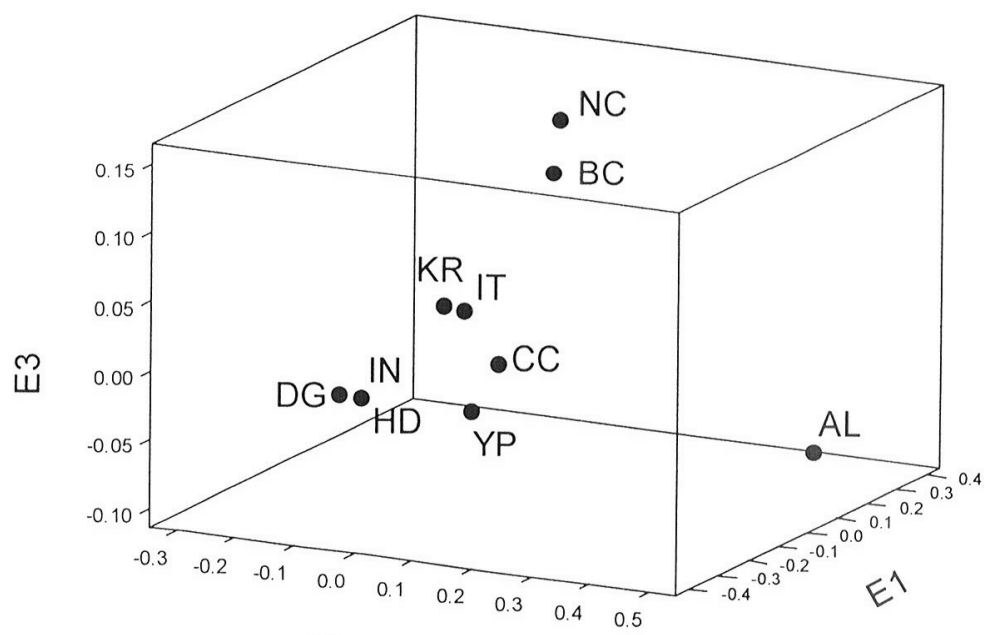

E2

Figure 3. $R$-matrix plot of populations based on mtDNA haplogroup frequencies. The first three eigenvectors account for $97.4 \%$ of the total variation: $\mathrm{E} 1=$ eigenvector $1(59.8 \%)$; E2 = eigenvector 2 (33.0\%); E3 = eigenvector 3 (4.6\%). Populations included are: AL = Aleut; $\mathrm{BC}=$ Bella Coola; $\mathrm{CC}=$ Chukchi; $\mathrm{DG}=$ Dogrib; HD = Haida; IN = Inuit; IT = Itel'men; KR = Koryak; NC = Nuu-Chah-Nulth; YP = Siberian Yupik (Siberian Eskimo).

Eskimos (Starikovskaya et al. 1998). As noted above, the Aleuts lacked CIR57 sequences (CHUO7), which represent the Eskimo-specific sublineage from hap$\operatorname{logroup} A$ defined by the $16265 \mathrm{G}$ mutation and the $A l u \mathrm{I} 11362$ site loss (Starikovskaya et al. 1998; Saillard et al. 2000).

$\boldsymbol{R}$-Matrix Analysis. The $R$-matrix analysis based on mLDA RFLP frequencies shows that the Aleuts are distinct from other populations because of their high frequency of mtDNA haplogroup $D$ (Figures 3 and 4). By contrast, haplogroup $D$ is present at low frequencies in other North Amcrican and Northeast Siberian populations. North American populations, including the Dogrib, Inuit, and Haida, clustered together because of their high frequencies of haplogroup $A$. Figure 5 plots the populations included in the $R$-matrix analysis based on frequencies of mtDNA HVS-I sequences. In this plot, the Aleuts cluster with Eskimo populations (including the West Greenland Eskimos and the Siberian Yupik) and the Chukchi, because of sharing specific HVS-I haplotypes with them, as also indicated in Table 3.

Median Network Analysis. The median network analysis of HVS-I sequences from the Alcuts and other circumarctic populations revealed a pattern of haplotypic relationships that was consistent with previous studies, but also added 


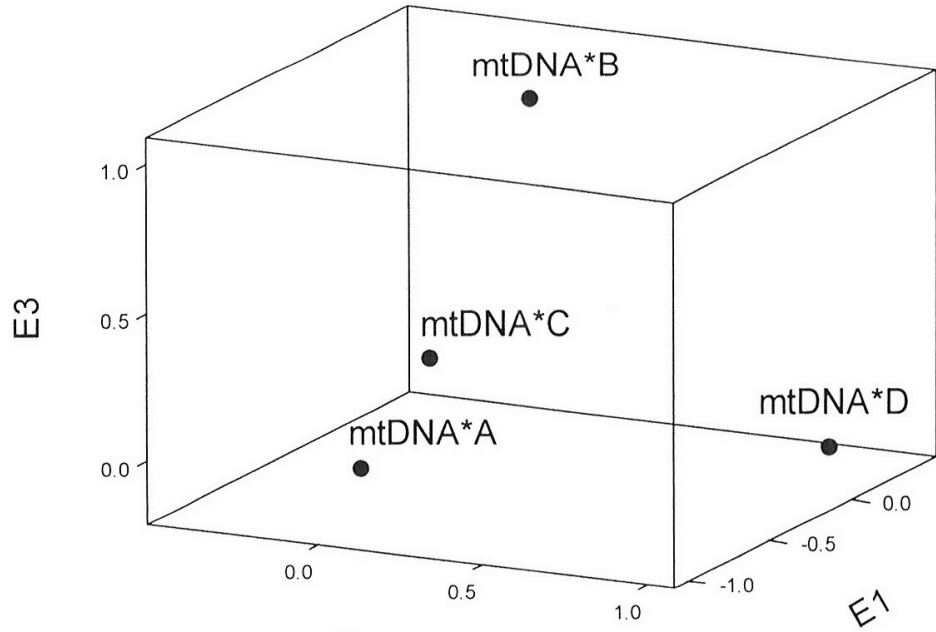

E2

Figure 4. Plot of alleles (mtDNA haplotypes) for Figure 3.

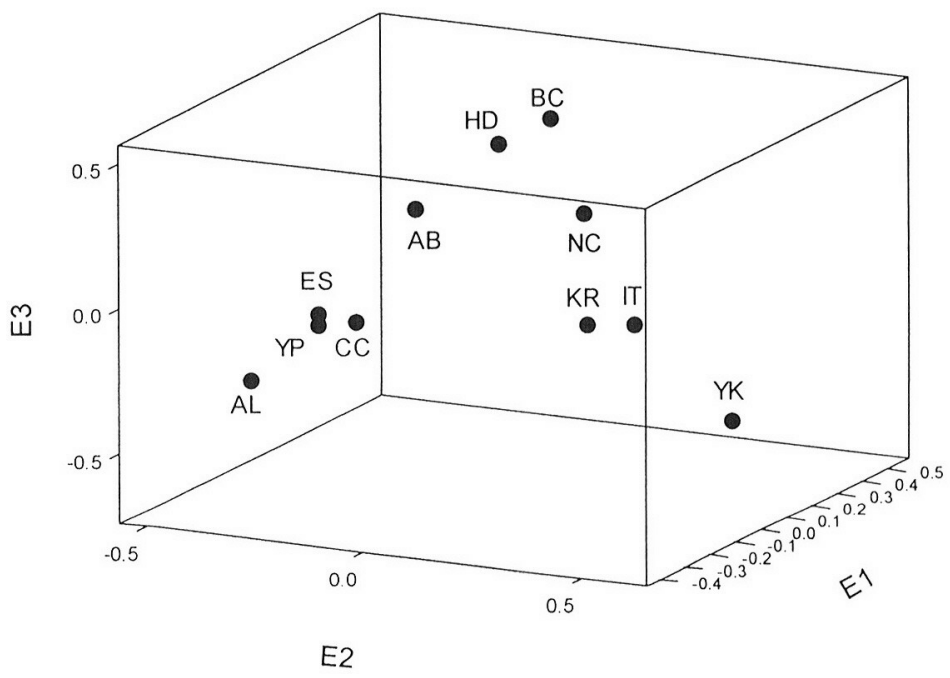

Figure 5. $R$-matrix plot of populations based on frequencies of mtDNA control region mutations. The first three eigenvectors account for $43.7 \%$ of the overall variation: E1 = eigenvector $1(15.4 \%)$; E2 = eigenvector $2(14.5 \%)$; E3 = eigenvector $3(13.8 \%)$. Populations included are: $\mathrm{AB}=$ Alaskan Athapaskan; $\mathrm{AL}=$ Aleut $\mathrm{BC}=$ Bella Coola; $\mathrm{CC}=$ Chukchi; $\mathrm{ES}=$ West Greenland Eskimo; HD = Haida; IT = Itel'men; KR = Koryak; NC = NuuChah-Nulth; YK = Yakima; YP = Siberian Yupik (Siberian Eskimo). 


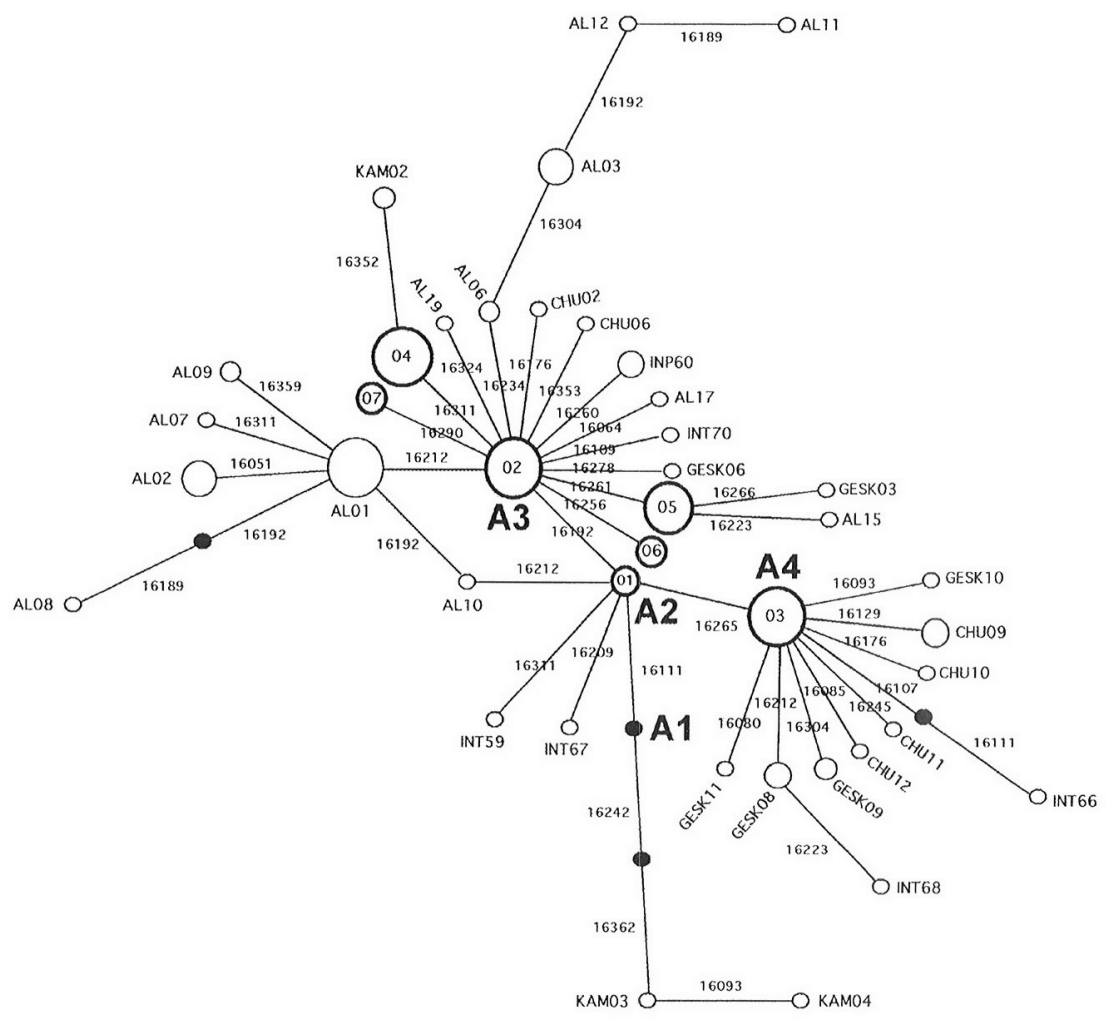

Figure 6. Haplogroup $A$ median network. The HVS-I sequences used in this analysis are from Aleuts (this study), Chukchi and Siberian Yupik (Siberian Eskimo) (Starikovskaya et al. 1998), Greenland Eskimos (Saillard et al. 2000), Inuit/Inupiaq (Shields et al. 1993), and Koryaks and Itel'men (Schurr et al. 1999). The size of each node or circle in the network corresponds to the number of sequences represented by each one. The numbering of the individual sequences follows from the nomenclature provided in the original papers, with the population designations being: $\mathrm{AL}=$ Aleuts, $\mathrm{CHU}=$ Chukotkan, $\mathrm{KAM}=$ Kamchatkan, GESK = Greenland Eskimo, INT = Inuit, and INP = Inupiaq. The sequences shared by more than one population (SH) are indicated by the nodes with numbers inside them. Shared sequences 01 and 02 correspond to the subtypes $A 2$ and $A 3$, which are central to the diversification of this haplogroup. The sequence numbers and number of mtDNAs belonging to them are as follows: SH01 = GESK01 (19); CHU01 (56); AL07 (4); KAM01 (2) [same as CIR61]; SH02 = CHU07 (3); AL12 (1); SH03 = CHU08 (25); GESK07 (35) [same as CIR57]; SH04 = GESK04 (8); AL19 (1); CHU03 (9) [same as CIR69]; SH05 = CHU04 (1); GESK02 (10); SH06 = GESK05 (1); AL13 (1); $\mathrm{SH} 07=\mathrm{CHU} 05$ (1); AL16 (3). 
new details to this growing picture of genetic diversity. To begin with, the hap$\operatorname{logroup} A$ network was built from four nodal haplotypes, Shared $01-03$ and ALO3 (Figure 6). Shared $O I$ and 02 correspond to haplotypes $A I$ and $A 2$ subtypes, respectively (Forster et al. 1996), and Shared 03 is the founding haplotype for the $16265 \mathrm{G}$ Eskimo sublineage. In a comparable way, ALO3 is the nodal haplotype for the Aleut-specific 16212 sublineage of haplogroup $A$. All other haplotypes derive from one of these four central nodes. Among these is another Aleut-specific branch or sublineage of haplogroup $A$ defined by the 16234 T mutation, which extends towards the top of this network. Not surprisingly, there were an additional four haplotypes (SHO4-07) shared by two or more circumarctic populations. Some of these shared haplotypes occurred in geographically distant groups, suggesting the possibility of recurrent mutations creating apparently identical haplotypes.

The haplogroup $D$ network showed a comparable structure to that of haplogroup $A$, but with fewer major nodes (Figure 7). The two main haplotypes, Shared 01 and 02 , correspond to subtypes $D I$ and $D 2$, respectively, of Forster et al. (1996). Shared 03 is equivalent to the rare but unusual $D 3$ haplotype (a.k.a., SIB40; Starikovskaya et al. 1998) that appears in the Koryaks (Schurr et al. 1999), Chukchi and Siberian Eskimos (Starikovskaya et al. 1998), and Japanese (Horai et al. 1996). Otherwise, the remaining $D$ haplotypes were unique to the population in which they appeared. As is evident from this network, D2 haplotypes occur primarily in Aleuts, with a few also being observed in the Chukchi and Siberian Eskimos, but none of these haplotypes have yet been seen in Amerindians. Interestingly, there was no overlap in the D2 haplotypes seen in Aleuts and Chukchi/Siberian Eskimos. This finding suggests that the two subbranches split some time ago, and/or the Chukotkan branch represents back flow from ancient Aleuts. Conversely, nearly all of the $D l$ haplotypes appeared in Amerindians and Athapaskans, with only a few of these haplotypes being present in Aleuts. Overall, the $D /$ cluster was more diverse than the $D 2$ cluster, but the $D 2$ cluster showed a few novel haplotypes.

Time Estimates. The estimated ages of specific clusters of HVS-I sequences are presented in Table 4 . For haplogroup $A$, the nodes defined by the following mutations were dated: $16111 \mathrm{~T}$ (A2 Native Americans); 16192T (A.3 Beringian populations); $16212 \mathrm{G}$ and 16234T (Aleuts); $16265 \mathrm{G}$ (Eskimos); and $16331 \mathrm{G}$ (Athapaskans). For haplogroup $D$, the nodes dated included $D 1$ and $D 2$.

The age of the $A l$ cluster obtained in this study $(29,964 \pm 13,350$ years $)$ was ancient, and slightly older than the age provided by Saillard et al. (2000) $(24,800$ $\pm 14,500$ years). However, both ages were essentially the same as those obtained with RFLP data from haplogroup $A$ mtDNAs in Native American populations (Torroni et al. 1992, 1993a; Starikovskaya et al. 1998). The same is also true for the $D /$ cluster, which represents all haplogroup $D$ mtDNAs in the Americas, as it was dated to $36,643 \pm 11,050$ years. These results, along with those of other recent studies (Silva et al. 2002), continue to point to the antiquity of these mtDNA 


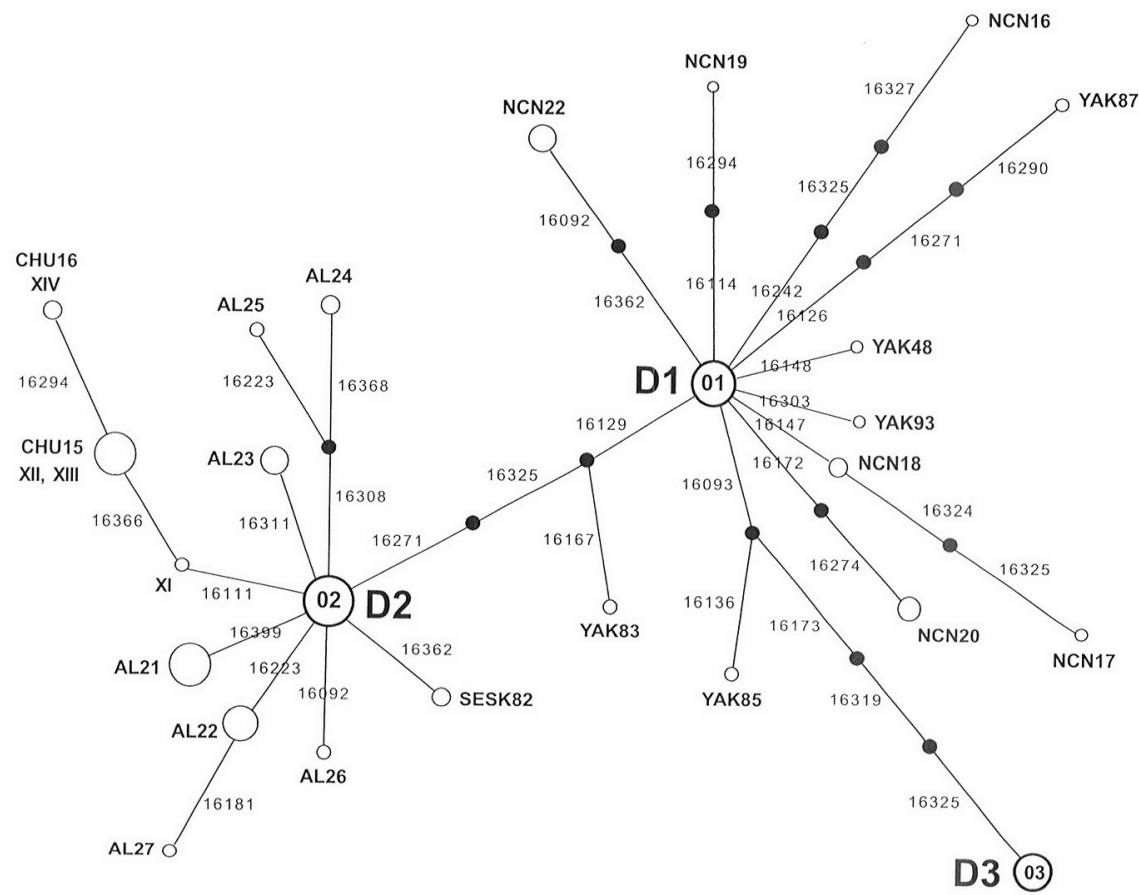

Figure 7. Haplogroup $D$ median network. The HVS-I sequences included in this analysis are from Aleuts (this study), Chukchi and Siberian Yupik (Siberian Eskimo) (Shields et al. 1993; Starikovskaya et al. 1998), Yakima (Shields et al. 1993); Nuu-Chah-Nulth (Ward et al. 1991), and Kamchatkan (Schurr et al. 1999). The size of each node or circle corresponds to the number of sequences represented by each one. The numbering of the individual sequences follows from the nomenclature provided in the original papers, with the population designations being: $\mathrm{AL}=$ Aleuts, $\mathrm{CHU}=$ Chukotkan, KAM = Kamchatkan, GESK = Greenland Eskimo, SESK = Siberian Eskimos; NCN = Nuu-Chah-Nulth; and YAK = Yakima. The Shared (SH) sequences are indicated by the nodes with numbers inside of them. Shared sequences 01 and 02 correspond to the subtypes D1 and D2 of Forster et al. (1996), which are central to the diversification of this haplogroup. The sequence numbers and number of mtDNAs belonging to them are as follows: SH01 = NCN (3) and YAK (2); SH02 = CHU14 (12), AL21 (79), and SESK81 (1); SH03 = KAM24 (2) and CHU13 (5). 
lineages in the New World, as demarcated by the $16111 \mathrm{~T}$ for haplogroup $A$, although Silva et al. (2002) have recently revised their entry dates to between $19,000-15,000$ YBP.

The estimated age of the Beringian $A$ (16192T) cluster in this study (13,117 $\pm 4,982$ years) was twice as old as that estimated by Saillard et al. (2000) (6300 \pm 3900 years). This difference probably reflects the inclusion of numerous Aleut mtDNAs from this cluster, as well as similar Eskimo types from Shields et al. (1993), in this analysis. Given the broad range of populations represented by this estimate, it scems reasonable to view this date as an approximate time depth for the emergence of the Beringian populations that were ancestral to Aleuts, Eskimos, and Athapaskan Indians.

The Aleut-specific $16212 \mathrm{G}$ cluster from haplogroup $A$ was also rather ancient, having arisen around 6540 years ago. Intriguingly, the $16212 \mathrm{G}$ cluster was about the same age as the $D 2$ cluster $(6035 \pm 2885$ years $)$ in this population. The concordance of the dates for these two sublineages in haplogroups $A$ and $D$ may thus signify the emergence of the Aleuts as a distinct population that had separated from the Eskimos. The Eskimos own emergence may have occurred around 4400 years ago, based on the diversity present in the Eskimo-specific $16265 \mathrm{G}$ sublineage of haplogroup $A$. In this regard, the addition of Yupik and Inupik HVSI sequences to those of the Greenland Eskimos of Saillard et al. (2000) increases the age of this cluster by nearly $50 \%$. Furthermore, the age of the Aleut $16234 \mathrm{~T}$ cluster of haplogroup $A$ was estimated (using the $A 2$ haplotype as its root) to be $3953 \pm 2417$ years old. Intercstingly, this date coincides with the timing of Laughlin's proposed expansion of so-called "Neo-Aleuts" (Laughlin 1980) (see below).

In addition, the age of the Na-Dene-specific $A 16331 \mathrm{G}$ sublineage was estimated at $3950 \pm 2417$ years. This date was generated from relatively few HVS-I sequences identified in Athapaskan groups by Torroni et al. (1993a) and Shields et al. (1993) in an expanded version of the data set used to generate the reduced median joining network shown in Figure 6. As such, it must be viewed as a preliminary estimate. However, if correct, it may indicate the slightly later emergence of Athapaskan populations relative to Aleuts and Eskimos.

\section{Discussion}

This study has confirmed the distinctiveness of the Aleuts relative to other Native American and circumarctic populations. Their mtDNA gene pool consists of only haplogroups $A$ and $D$, with the latter constituting over $70 \%$ of these haplotypes. While these two haplogroups predominate within other circumarctic populations, haplogroup A represents the majority of all of their mtDNAs. Beringian populations, including the Eskimos, Na-Dene Indians, and northeastern Siberians, also share a number of HVS-I haplotypes from haplogroups $A$ and $D$. By comparison, the Aleuts share fewer haplotypes with these groups, and primarily 
with the Chukchi and Siberian Eskimos. These affinities are also seen in the $R$-matrix analysis, with Aleuts showing closer relationships to Chukotkan populations than to others on the Alaskan side of the Bering Strait.

Genetically, the Aleuts show little in common with Kamchatkan populations, the Koryaks and Itel'men. Kamchatkan groups have few haplogroup $A$ and $D$ mtDNAs, and exhibited mostly haplogroup $C, G$, and $Y$ haplotypes (Schurr et al. 1999), which do not appear in Aleuts. In fact, contemporary Koryaks and Itel'men show stronger genetic affinities with eastern Siberian and Amur River populations than to those of the North Pacific Rim (Schurr et al. 1999). This pattern likely reflects the relatively recent immigration to Kamchatka of new tribes from the Siberian mainland region ( $6000-8000$ YBP), although genetic contributions from ancient Beringian populations may be evident in the Koryak and Itel'men gene pools.

The genctic data from Koryak and Itel'men populations are generally consistent with the archeological evidence of the Kamchatka peninsula. This region was first colonized approximately 14,000 years ago by a culture subsisting on big game hunting and salmon fishing, while employing bifacial projectile points similar to the Late Paleolithic Paleo-Indian stemmed projectile point industry of western North America (Arutiunov 1988; Arutiunov and Sergeev 1990a; Dikov 1990, 1994). By 10,860 YBP, this culture was superseded by a technology using bifacially retouched leaf-shaped microblades and having stone labret ornamentation. These innovations, along with the development of nontoggling, multibarbed harpoon technologies for hunting sea mammals demarcate the beginnings of the proto-Eskimo-Aleut cultural tradition in northeast Siberia (Arutiunov and Sergeev 1990a, b; Dikov 1990). As a result, the emergence of the Palcoarctic cultural tradition in northeastern Siberia during the Holocene is probably linked with the expansion of ancient Beringian peoples into the Aleutian Islands, which, based on archeological data from the castern Aleutians, dates to around $8500 \mathrm{BP}$ at Anangula and Hog Island (Laughlin 1980; Knecht and Davis 200I). Judging from these genetic and archeological data, ancestral Alcuts crossed the Bering Land Bridge to enter the eastern Aleutians, rather than island hopping from the Kamchatka Peninsula into the western Aleutians.

The colonization dates for the Aleutian Islands are somewhat older than the coalescence times for the Aleut-specific $16212 \mathrm{G}$ cluster from haplogroup A (6539 \pm 3511 years $)$ and the $D 2$ cluster $(6035 \pm 2885$ years $)$ in this population. However, if the standard errors associated with these estimates are taken into consideration, the coalescence dates are congruent with the archeological data. As such, they appear to demarcate the emergence of the Aleuts as a population distinct from other ethnic groups taking form in the Beringian region. Additional support for this interpretation comes from ancient DNA studies of prehistoric Aleut populations dating to 3000-4000 years ago, which show nearly identical frequencies of haplogroups $A$ and $D$ as their modern antecedents (Hayes 2002; Hayes and O'Rourke 2000; O'Rourke et al. 2002). Furthermore, some reduction in genetic diversity must have resulted from the dramatic demographic impact of Russian 
colonization of Aleut populations. Together, these lines of evidence imply that the coalescence estimates can be considered minimum time depths for these mtDNA sublineages, hence, the emergence of the Alcuts as a distinct population.

The coalescence dates of the Aleut $16212 \mathrm{G}$ and $D 2$ clusters also suggest that Aleuts split from related proto-Eskimo groups before or around this same time period. If correct, then the timing of this bifurcation is generally compatible with dates estimated for the same separation based on linguistic and classical blood group marker data (Harper 1980; Woodbury 1984). In addition, the Aleut $16212 \mathrm{G}$ sublineage of haplogroup $A$ is not present in Eskimo populations, and D2 haplotypes are present only in Chukchi and Siberian Eskimos (and one Alaskan Athapaskan), and at low frequencies. Moreover, all Eskimoan groups (Yupik and Inupik) possess the $16265 \mathrm{G}$ sublineage of haplogroup $A$, which is dated at $4398 \pm$ 1574 years, whereas the Aleuts lack these haplotypes altogether. Thus, it appears that Eskimoan populations became genetically distinctive as an ethnic group somewhat later than the Aleuts, but also shortly before the Na-Dene Indians, whose own $16331 \mathrm{G}$ sublineage of haplogroup $A$ dates to approximately $3950 \pm$ 2417 years.

These new mtDNA data also allow us to test different models for transitions in morphological characteristics that have been identified in ancient Aleut populations. As first noted by Hrdlicka (1945), two distinct cranial morphologies are present in the Aleut skeletal remains of the eastern Aleutians. According to Laughlin (1980), the early inhabitants of the Aleutian Islands, the "Paleo-Aleuts," had dolichocephalic crania, and these individuals evolved into the "Neo-Aleuts," who had brachycephalic crania. This change supposedly first took place among the residents of the eastern Aleutians around 4000 years ago, and spread into the smaller communities of the central and western islands (Laughlin 1980). This time period fits nicely with the age of the Aleut-specific $16234 \mathrm{~T}$ cluster of hap$\operatorname{logroup} A$, which is $3953 \pm 2417$ years. However, the most recent $C^{14}$ dating of this cranial series suggest there is no temporal distinction between Paleo-Aleuts and Neo-Aleuts (Hayes and O'Rourke, personal communication). Thus, there may not have been such a distinct morphological transition as previously thought, and this particular mtDNA cluster may simply be a unique branch of haplogroup $A$ that arose in Aleuts some 4000 years ago, perhaps because of the founder effect and geographic isolation.

These observations provide a reference point from which to evaluate other genetic data obtained from Aleut populations. Recently, Derbeneva et al. (2002) published complete mtDNA sequences of a small sample from the terminus of the Aleutian Islands, the village of Nikolskoye, Bering Island. They sampled only 30 individuals, with approximately half (15) of them being born on Bering and the remainder having been relocated to this community in the 1960s from Medniy Island, the second of the Commander Islands. These two islands were uninhabited until 1842, when Russians transplanted Aleuts from Atka, Attu, and Unalaska, together with native and Siberian Russians, gypsies, and Native Americans. Similar to Medniy and Bering, the Pribilof Islands (St. Paul and St. George) also con- 
tained no Aleut settlements until Russian colonization. However, because they were breeding grounds for fur-bearing seals, both pairs of islands became sites of massive fur harvests, hence, human settlements.

This complex population history is reflected in the mtDNA studies of Aleut populations. Both Merriwether et al. (1995) and we (this paper) detected haplogroups $A$ and $D$ in the contemporary populations of the Aleutian Islands (with larger sample sizes of 76 and 179 , respectively). By contrast, Derbeneva et al. (2002) described a monomorphic sample, with only haplogroup $D$ being present in the Aleuts of Bering Island. They attributed the 'loss' of haplogroup $A$ on Bering and Medniy to genetic drift, "because of the genocide of the natives at the end of the 18th century" (Derbeneva et al. 2002:420). However, as noted above, Bering was not settled until 1842, and both haplogroups $A$ and $D$ are known to be present in the parental populations of Unalaska and Atka (Rubicz et al. 2001). Therefore, the likelihood that this loss of $\mathrm{mtDNA}$ lineage in a population of more than 300 individuals was due to genetic drift is extremely low.

We statistically tested the hypothesis that genetic drift caused the loss of haplogroup $A$ from the Bering Aleuts. Without the intervention of selection against the $A$ haplogroup, the variance due to stochastic processes can be estimated by $\sigma_{X}^{2}=q(1-q) / 2 N_{e}$, with $q=0.29$ and $N_{e}$ being estimated as 0.3 of the total population size. Thus, in a population of 300 individuals, the variance will fluctuate $\sigma_{x}^{2}= \pm 0.001 /$ generation or roughly 0.006 in six generations. Consequently, the most parsimonious explanation for the absence of haplogroup $A$ in Bcring Aleuts is that most of the 30 individuals sampled by Derbeneva et al. (2002) are closely related.

This interpretation is consistent with the history of the Commander Islands. When Russian authorities closed the Medniy community, many Aleuts with familial connections were relocated to Bering Island, while the remainder moved to Kamchatka. In this regard, our research team visited Bering Island during the same year as Derbeneva et al. (2002) and took blood specimens from 100 individuals, including the same persons that they had analyzed. As a result, we should be able to test whether the fixation of haplogroup $D$ in the Bering Aleuts is due to genetic drift. In addition to the family histories that we collected from these persons, we are currently analyzing the extensive genealogies from both Commander Islands that trace familial relations to the founders of 1842. These were collected by the cminent Russian population geneticist, Yuri G. Rychkov, in the early 1960s. Overall, these findings reiterate the importance of collecting extensive genealogies in field populations.

Peopling of the Americas. While there is general agreement that ancestral New World populations originated in Asia and entered the Americas by way of the Bering Land Bridge, the specific Asian source or sources, the number of migrations involved, and the timing of these events remain a matter of controversy. Greenberg et al. (1986) compared genetic (classic blood group markers), linguistic, and dental evidence in Native American populations, and, on this basis, pro- 
posed a so-called "new synthesis," in which the New World was colonized through three migrations represented by the Amerind, Na-Dene, and Eskimo language families. All subsequent studies focusing on mtDNA variation in Native Americans have attempted to confirm or refute its predictions of population origins and affinities (Torroni et al. 1992, 1993a, b; Horai et al. 1993; Lorenz and Smith 1996; Merriwether et al. 1995; Forster et al. 1996; Bonatto and Salzano 1997).

A common finding of all these studies is that haplogroups $A-D$ constitute the vast majority of mtDNAs in Native American populations. In addition, some have revealed that a small percentage of mtDNAs from North American populations belong to haplogroup $X$ (Torroni et al. 1992; Forster et al. 1996; Brown et al. 1998). Most of them favor a model of New World colonization in which one to two major expansions of ancient Asian peoples gave rise to Amerindian populations, and generally indicate that this colonization was early (pre-15,000 YBP). The most recent attempt to quantify the number of migrations to the New World suggests that a single, early migration $(15,000-20,000$ years ago) gave rise to all Native American populations (Silva et al. 2002). This date is consistent with those dates obtained in this study for the $A 2$ and $D /$ clusters, 29,964 $\pm 13,350$ and $36,643 \pm 11,050$ years old, respectively, which represent two founder mtDNA lineages for Native Americans. However, these findings still do not fully resolve the issue of the origins of Beringian populations.

Several studies, including this one, have indicated that Beringian populations (Aleuts, Eskimos, and Athapaskans) emerged after the initial peopling of the Americas at approximately 14,000-12,000 years ago. This expansion is demarcated by the presence of $A 3(16192 \mathrm{~T})$ and $D 2$ haplotypes in these populations, as well as a number of population specific sublineages of haplogroup $A$ in Aleuts (16212G, 16234C), Eskimos (16265G), and Athapaskan Indians (16331G). These sublineages show genealogical links to $A$ and $D$ haplotypes present in Amerindians, but are not found in these populations. In addition, all Beringian populations are nearly devoid of haplogroup $C$ and $D$ mtDNAs, and lack haplogroup $X$ mtDNAs altogether. Thus, it would appear that the ancestors of Beringian populations possessed a subset of the haplotypes that were present in ancestral Amerindian populations, and hence may have arisen independently of them.

An alternative explanation for this pattern of genetic diversity is that ancestral Beringian populations evolved from Amerindian populations inhabiting North America during the last glacial maximum. Once the northern reaches of this continent became inhabitable after the glacial ice sheets receded, the Beringians then expanded northward, and, in the process, moved into the remaining portions of the former Beringian platform, including the northeastern corner of Siberia. In fact, this scenario is essentially the same as the "East Americanoid" theory put forward by Franz. Boas in the early part of the 20th century (Bogoras 1902; Jochelson 1908; Boas 1912, 1928). In this model, the back-migration of American cultures from east to west across the North Pacific produced the Chukchi, Koryak, Kamchadal, Yukagir, and Nivkhs (Boas 1905). The peoples on 
either side of the North Pacific were then separated at the Bering Strait by the intrusion of the Eskimos, a people who were culturally and morphologically distinct and purportedly originated in Central Canada (Boas 1905, 1912).

However, modern genetic data refute certain aspects of this particular model. For example, as this study has shown, the Aleuts have some genetic affinities with Chukchi and Siberian Eskimo populations, but virtually none with Kamchatkan populations, or Yukagirs. In addition, Amur River populations such as the Nivkhs are genetically distinctive from northeastern Siberian populations (Torroni et al. 1993b; Lell et al. 1997, 2002; Schurr et al. 2000). Furthermore, Eskimo populations also show stronger affinities with other Beringian groups than with Amerindian populations, and do not appear to have originated in Central Canada. Finally, the $A 3, A 4$, and $D 2$ haplotypes present in Beringian populations do not occur in their putative progenitor populations, Amerindians. Thereforc, Beringian populations seem to represent a post-glacial expansion distinct from the one giving rise to Amerindian populations, but one having genetic connections to the earlier immigrants to the New World.

Overall, Aleut mtDNAs are most similar to those of Northeastern Sibcrian and North American populations, which differ from those present among Amerindians and Asians outside of northeastern Siberia. These Beringian populations, including the Eskimos, Na-Dene Indians, and coastal Siberians, share HVS-I haplotypes and mtDNA haplogroups $A$ and $D$. If haplogroups $B$ and $C$ in these populations are the result of recent admixture, it provides evidence against a single migration of people from Asia to the Americas with all four haplogroups. Instead, this suggests that there were at least two migrations. The first migration, consisting of the ancestors of the Amerindians, may have taken place some time around 30,000-25,000 years ago. The Beringian groups would have emerged lat$\mathrm{cr}$, around 13,000 years ago, some of which may have migrated from Siberia to the Americas around this time. The Aleuts appear to have differentiated from other Beringian populations more than 6000 years ago, with their closest relatives being the Siberian Eskimos and Chukchi, rather than New World Eskimos and $\mathrm{Na}$-Dene Indian populations. Aleuts are not closely related to the populations of the Kamchatka Peninsula (the Koryaks and Itel'men), which supports Laughlin's hypothesis that they crossed the Bering Land Bridge and entered the castern Aleutians, rather than island hopping from the Kamchatka Peninsula into the western Aleutians. The results of this study indicate that the Aleuts represent one of the last human expansions into the New World.

Acknowledgments We would like to thank Aleut elder Alice Petrivelli and all Aleut individuals who participated in this study. This work was supported by the National Science Foundation through grant No. OPP-990590 (MHC), Sigma Xi and Ida H. Hydc (RR), and the Southwest Foundation for Biomedical Research (TGS).

Received 26 March 2003; revision received 23 May 2003. 


\section{Literature Cited}

Anderson, S., A.T. Bankier, B.C. Barrell et al. 1981. Sequence and organization of the human mitochondrial genome. Nature 290:457-465.

Arutiunov, S.A. 1988. Koryaks and Itel'men: Dwellers of the smoking coast. In Crosswads of Continents, W.W. Fitzhugh and A. Crowell, eds. Baltimore, MD: Smithsonian Institution Press, $31-35$.

Arutiunov, S.A., and D.A. Sergeev. 1990a. Issues of the ethnic history of the Bering Sea. Chapter 1. Problems in the study of the ethnic history of the northwestern coastline of the Pacific coast. Soviet Anthropol. Archeol. 28:50-61.

Arutiunov, S.A., and D.A. Sergeev. 1990b. Issues of the ethnic history of the Bering Sca. Chapter 8. The role of ancient Eskimo culture in the ethnic history of the northern Pacific basin. Soviet Anthropol. Archeol. 28:62-77.

Bandelt, H.-J., P. Forster, B.C. Sykes et al. 1995. Mitochondrial portraits of human populations using median networks. Genetics 141:743-753.

Bergstand, K. 1959. Aleut dialects of Atka and Attu. Transactions of the American Philosophical Society $49: 3$.

Bernstein, F. 1931. Die geographische verteilung der blutgruppen und ihre anthropologische bedeutung. Comitato Italiano per lo Studio deo Problemi della Populazione. Istituto Poligrafico dello Stato, Rome, 227-243.

Black, L. 1983. Some problems in the interpretation of Aleut prehistory. Arctic Anthropology 20(1):49-78.

Black, R. 1974. Late-Quaternary sea level changes, Umnak Island, Aleutians: Their effects on ancient Aleuts and their causes. Quatemary Research 4:264-281.

Boas, F. 1905. The Jesup North Pacific Expedition. In Proceedings of the Thirteenth International Congress of Americanists. Easton, PA: Eschenbach Printing, 91-100.

Boas, F. 1912. The history of the Amcrican race. Annals of the American Academy of Sciences. $21: 177-183$.

Boas, F. 1928. Migrations of Asiatic races and cultures to North America. Science Monthly 29:110-121.

Bogoras, W. 1902. Folklore of northeastern Asia as compared with that of northwestern America. Amer: Anthropologist 4:577-683.

Bonatto, S.L., and F.M. Salzano. 1997. A single and early migration for the peopling of the Americas supported by mitochondrial DNA sequence data. Proc. Natl. Acad. Sci. USA 94:18661871.

Brown, M., S. Hosseini, A. Torroni et al. 1998. MtDN^ haplogroup X: An ancient link between Europe/West Asia and North America? Am. J. Hum. Genet. 63:1852-1861.

Cavalli-Sforza, L., and W. Bodmer. 1971. The Genetics of Human Populations. San Fransisco, CA W.H. Freeman Co, 491.

Derbeneva, O.A., R.I. Sukernik, N.V. Volodko et al. 2002. Analysis of mitochondrial DNA diversity in the Aleuts of the Commander Islands and it implications for the genctic history of Beringia. Am. J. Hum. Genet. 71:415-421.

Dikov, N.N. 1990. The origin of the aboriginal populations of America. Soviet Anthropol. Archeol. 28:12-29.

Dikov, N.N. 1994. The Paleolithic of Kamchatka and Chukotka and the problem of the peopling of America. In Anthropology in the North Pacific Rim, W.W. Fitzhugh, V. Chausonnet, eds. Washington, D.C., Smithsonian Institution Press, 87-95.

Forster, P., R. Harding, A. Torroni et al, 1996. Origin and evolution of Native American mtDNA variation: A reappraisal. Am. J. Hum. Genet. 59:935-945.

Greenberg, J., C.G. Turner, and S.L. Zegura. 1986. The settlement of the Americas: A comparison of the linguistic, dental, and genetic evidence. Curr. Anthropol. 4:477-497.

Harpending, H., and T. Jenkins. 1973. Genetic distance among Southern African populations. In 
Methods and Theories of Anthropological Genetics, M.H. Crawford, and P. Workman, eds. Albuquerque, NM: University of New Mexico Press, 177-199.

Harpending, H., and R. Rogers. 1984. ANTANA: A package for multivariate data analysis. Distributed by the authors.

Harper, A.B. 1980. Origins and divergence of Aleuts, Eskimos and American Indians. Ann. Hum. Biol. 7:547-554.

Hayes, M.G. 2002. Mitochondrial DNA variation of ancient Aleuts. Ph.D. dissertation, University of Utah, Salt Lake City, UT.

Hayes, M.G., and D.H. O'Rourke. 2000. Replacement versus continuity in the prehistoric North American Arctic as assessed by ancient mtDNA. Am. J. Phys. Anthropol. Suppl. 30:174-175.

Horai, S., R. Konodo, Y. Nakagawa-Hottori et al. 1993. Peopling of the Americas, founded by four major lineages of mitochondrial DNA. Mol. Biol. Evol. 10:23-47.

Horai, S., K. Murayama, K. Hayasaka, et al. 1996. MtDNA polymorphism in East Asian populations, with special reference to the peopling of Japan. Am. J. Hum. Genet. 59:501-509.

Hrdlicka, A. 1945. The Aleutian and Commander Islands and Their Inhabitants. Philadelphia, PA: The Wistar Institute of Anatomy and Biology.

Jochelson, W.R. 1908. The Jesup North Pacific Expedition. Vol. 6, The Koryak. Memoirs of the American Museum of Natural History. Leiden, NY: Amcrican Museum of Natural History.

Knecht, R.A., and R.S. Davis. 2001. A prehistoric sequence for the eastern Aleutians. University of Oregon Anthropological Papers 58:269-288.

Lantis, M. 1984. Alcut. In Handhook of North American Indians. Vol. 5, Arctic, D. Damas, ed. Washington, DC: Smithsonian Institution Press, 161-184.

Laughlin, W. 1963. Eskimos and Aleuts: Their origins and evolution. Science 142:633-645.

Laughlin, W. 1980. Aleuts: Survivors of the Bering Land Bridge. New York, NY: Holt, Reinhart and Winston.

Laughlin, W., and G. Marsh. 1951. A new view of the history of the Aleutians. Arctic Anthropology $4: 74-88$

Lell, J.T., M.D. Brown, T.G. Schurr et al. 1997. Y-chromosome polymorphisms in Native American and Siberian populations: Identification of founding Native American Y-chromosome haplotypes. Hum. Genet. 100:536-543.

Lell, J.T., R.I. Sukernik, Y.B. Starikovskaya et al. 2002. The dual origins and Siberian alfinities of Native American Y chromosones. Am. J. Hum. Genet. 70:192-206.

Lorenz, J.G., and D.G. Smith. 1996. Distribution of four founding $m$ tDNA haplogroups among Native North Americans. Am. J. Phys. Anthropol. 98:411-430.

Marsh, G.H., and M. Swadesh. 1951. Kleinschmidt Centennial V: Eskimo Aleut correspondences. International Journal of American Linguistics 17(4):209-216.

Merriwether, D.A., F. Rothhammer, and R.E. Ferrell. 1995. Distribution of the four founding lineage haplotypes in Native Americans suggests a single wave of migration for the New World. Am. J. Phys. Anthropol. 98:411-430.

O'Rourke, D.H., M.G. Hayes, and S.W. Carlyle. 2000. Spatial and temporal stability of mtDNA haplogroup frequencies in native North America. Hum. Biol. 72:15-34.

Ouslcy, S. 1995. Relationships between Eskimos, Amerindians, and Aleuts: Old data, new perspectives. Hum. Biol. 67(3):427-458.

Rubic\%, R. 2001. Origins of the Aleuts: Moleculer Perspectives. Master's thesis, Universily of Kansas, Lawrence, KS.

Rubicz R., T.G. Schurr, and M.H.Crawford. 2000. Mitochondrial DNA diversity in modern Aleuts and their genetic relationship with other circumarctic populations. Paper presented at the Arctic Anthropology meetings, University of Kansas.

Rubicz, R., T.G. Schurr, and M.H. Crawford. 2001. Mitochondrial DNA diversity in modern Aleut populations. Am. J. Hum. Biol. 13(1):139.

Saillard, I., P. Forster, N. Lynnerup et al. 2000. MIDNA variation among Greenland Eskimos: The edge of the Beringian expansion. Am. J. Hum. Genet. 67:718-726.

Schurr T., S. Ballinger, Y. Gan et al. 1990. Amerindian mitochondrial DNAs have rare Asian mutations 
at high frequencies, suggesting they derived from four primary maternal lineages. $\mathrm{Am}$. J. Hum. Genet. 46:613-623.

Schurr, T.G., Y.B. Starikovskaya, R.I. Sukernik et al. 2000. Mitochondrial DNA diversity in lower Amur River populations, and its implications for the genetic history of the North Pacific and the New World. Am. J. Phys. Anthropol. 30:274-275.

Schurr, T.G., R. Sukernik, Y. Starikovskaya et al. 1999. Mitochondrial DNA variation in Koryaks and Itel'men: Population replacement in the Okhotsk Sea-Bering Sea region during the Neolithic. Am. J. Phys. Anthropol. 108:1-39.

Schurr, T.G, and D. Wallace. 1999. mtDNA variations in Native Americans and Siberians and its implications for the peopling of the New World. In Who Were the First Americans? R. Bonnichsen, ed. Proceedings of the $58^{\text {th }}$ Annual Biology Colloquium, Oregon State University, Corvallis, 41-77.

Shiclds, G., A. Schmiechen, B. Frazier et al. 1993. MtDNA sequences suggest a recent evolutionary divergence for Beringian and northern North American populations. Am. J. Hum. Genet. 53:549-562.

Silva, W.A., S.L. Bonatto, A.J. Holanda et a1. 2002. Mitochondrial Genome Diversity of Native Americans Supports a Single Early Entry of Founder Populations into America. Am. J. Hum. Genet. $71: 187-192$.

Starikovskaya, Y.B., R.I. Sukernik, T.G. Schur et a1. 1998. MtDNA diversity in the Chukchi and Siberian Eskimos: Implications for the genetic history of ancient Beringia and the peopling of the New World. Am. J. Hum. Genet. 63:1473-1491.

Szathmary, E., and N. Ossenberg. 1978. Are the biological differences between North Amcrican Indians and Eskimos truly profound? Curr. Anthropol. 19(4):673-701.

Torroni, A., T. Schurr, M. Cabcll et al. 1993a. Asian affinities and continental radiation of the four founding Native American mtDNAs. Am. J. Hum. Genet. 53:563-590.

Torroni, A., T. Schurr, C. Yang et al. 1992. Native American mitochondrial DNA analysis indicates that the Amerind and the Nadene populations were founded by two independent migrations. Genetics 130:153-162.

Torroni, A., R. Sukernik, T. Schurr et al. 1993b. Mitochondrial DNA variation of aboriginal Siberians reveal distinct genetic affinities with Native Americans. Am. J. Hum. Genet 53:591-608.

Turner, C. 1983. Dental evidence for the peopling of the Americas. In Early Man in the New World, R. Shutler, ed. Beverly Hills, London, New Delhi: Sage Publications, 147-157.

Ward, R.H., B.L. Frazier, K. Dew-Jager et al. 1991. Extensive mitochondrial diversity within a single Amerindian tribe. Proc. Natl. Acad. Sci. USA 88:8720-8724.

Ward, R.H., A. Redd, D. Valencia et al. 1993. Genetic and linguistic differentiation in the Americas. Proc. Natl. Acad. Sci. USA 90:10663-10667.

Woodbury, A.C. 1984. Eskimo and Aleut Languages. In Handbook of North American Indians. Vol. 5 , Arctic, W.C. Sturtevant, ed. Washington, D.C.: Smithsonian Institution Press. 